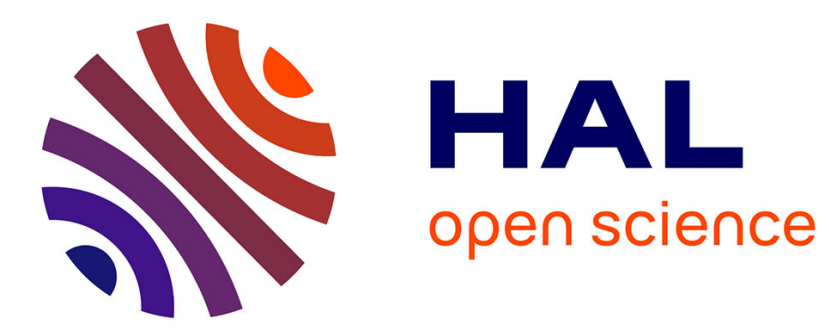

\title{
Serialization in the age of finance capitalism
}

David Buxton

\section{To cite this version:}

David Buxton. Serialization in the age of finance capitalism. Matt Seybold; Michelle Chihara. The Routledge Companion to Literature and Economics, Routledge, pp.406-414, 2019, 9781138190870. 10.4324/9781315640808-38 . hal-02321361

\section{HAL Id: hal-02321361 https://hal.parisnanterre.fr/hal-02321361}

Submitted on 21 Oct 2019

HAL is a multi-disciplinary open access archive for the deposit and dissemination of scientific research documents, whether they are published or not. The documents may come from teaching and research institutions in France or abroad, or from public or private research centers.
L'archive ouverte pluridisciplinaire HAL, est destinée au dépôt et à la diffusion de documents scientifiques de niveau recherche, publiés ou non, émanant des établissements d'enseignement et de recherche français ou étrangers, des laboratoires publics ou privés. 


\title{
SERIALIZATION IN THE AGE OF FINANCE CAPITALISM
}

\author{
David Buxton
}

How might we critically approach the television series in a way that accounts for the nature of its form, a form which carries both ideological and economic ramifications? Few would deny that series fit awkwardly into an academic framework, by reason of their industrial volume, and because audience interest declines rapidly once they have disappeared from the screen. One could try to constitute a canon as in literary or film studies, but it is nevertheless difficult, if not impossible, to fully circumscribe a "work" sometimes extending to hundreds of episodes. ${ }^{1}$ The choice made here is a synthesis, in very general terms, which encompasses the more commercial network series and the "quality" series produced by cable television, and which integrates on an equal basis the three terms evoked in the opening sentence: ideology, economy, and ... form.

Any direct attempt to relate the ideological and economic dimensions of a particular series is more or less doomed to the reductionism of the base/superstructure model. We would do well to remember, however, that the very principle of seriality in its two historical forms, the serial and the series, was determined from the outset by commercial factors, beginning with the serialized publications, both in 1836, of Balzac's La Vieille Fille in France, and of Dickens' The Pickwick Papers in Britain. In effect, serialization was invented to increase and consolidate the circulation of the periodic press. For similarly commercial reasons, the recurring main character was a mainstay of popular genre literature, especially the detective novel. ${ }^{2}$ For the sake of argument, in purely formal terms, the television series can be seen as a derivative of what was originally a literary form. Seriality in its different guises has never existed outside of considerations of economic rationality (unless one wants to stretch a point). The daytime serial and the weekly series were present at the beginning of the television medium as privileged forms that enabled the advance sale of advertising time on the basis of relatively predictable audience levels. I propose therefore to explore the link between the economic and the ideological through the mediation of form, especially through the internal variations within the series form. For my purposes, the internal form adopted by the series at a given historical moment preempts the analysis of the content of any particular series (and thus, a fortiori, of any particular episode)

Three theoretical suppositions anchor my argument. First, Adorno's claim that "form ... is itself sedimented content" (Adorno, Adorno, and Tiedeman, 1997; see also the discussions in Jameson, 1990, 1992). The context here is a philosophical argument about the autonomy of "authentic" art, and Adorno would surely not have approved of its application to products of 
the culture industry. Yet in a little cited article on television fiction when it was still in its infancy, Adorno (1954) does seem implicitly to countenance such a reading. The principle of recurrence, inherent to the series form, is necessarily in tension with the criteria of realism that govern its perceived quality. The "pseudo-realism" denounced by Adorno is less a question of cheap sets and production values than of the sheer artificiality that stems from the recurrence of the same characters, leading to psychological stereotypes and predictable narratives.

Second, in an important book of neo-formalist criticism, Caroline Levine (2015) proposes a conceptual term borrowed from the world of design, affordance, to describe the potential uses or constraints latent in materials (glass, cotton) or in designs (fork, doorknob). From her reading of Foucault's Discipline and Punish, Levine argues that forms are always "portable" from one domain to another, like the monastic timetable that was subsequently transposed to schools, hospitals, and prisons. By the same token, the arrangement of elements within a social institution like, for example, the stock exchange could collide with other cultural forms in unforeseen and unlikely ways, due to its affordances.

Third, the distinction made by Marx in a "forgotten" chapter of Capital between formal and real subsumption to capital (Marx, 1990). Marx distinguished between formal subsumption in which the intervention of capitalist relations intervenes after the fact of artisanal production, and real subsumption wherein the intervention of capital occurs in the very organization of production. This comes in the context of a discussion of the transition between primitive and advanced capitalism, and between absolute surplus value based on the length of the working day and relative surplus value based on the integration of capitalist forms of organization of the workplace. Formal and real subsumption may seem at first sight somewhat removed from the subject at hand, but the distinction, extrapolated from the narrow context of Marx's original argument, is nevertheless essential to the notion of an asymmetrical periodization of capitalism, its uneven evolution, and the deepening of its internal logic. Real subsumption, which implies the intervention of capital in the design and conception stages of production, should be understood as a historical process whose absolute horizon is in all probability unattainable in anthropological terms (a society in which no human activity would exist outside of the extraction of surplus value). Nevertheless, Jason Read has argued convincingly that real subsumption extends to the production of a capitalist subjectivity, a form of continual existential adaptation. In other words, the (economic) concept of real subsumption involves an ideological dimension, wherein its translation into subjectivity is a contested historical process (Read, 2003).

\section{The "classic" series}

During the 1950s, television seriality took the form of the anthology: a generic theme with different situations and characters each week. The best-known examples were The Twilight Zone (1959-62) and Alfred Hitchcock Presents (1955-65), in which seriality is most directly expressed through the continuity of the anchorman (Rod Serling and Alfred Hitchcock). The twenty-five-minute format, more common in the 1950s for filmed series, was conducive to adaptations of the short story form practiced by genre writers like Richard Matheson and Harlan Ellison. ${ }^{3}$ The principle of weekly recurring characters came to dominate only in the latter half of the decade.

In the classic form of the series, a resolved, stand-alone drama is usually organized around one or several recurring characters against the same backdrop. Seriality is actually minimal, and these shows are closer to semi-anthologies than later series with multiple characters and storylines. Week after week, the main recurring character confronts a different 
problem posed by visitors ("tonight's guests"), as if the slate were forever wiped clean and time suspended. This relative minimalism accounts for the exceptional longevity of Gunsmoke, originally a half-hour radio series, which ran from 1955 to 1975 and Bonanza, which ran from 1959 to 1973. The western genre dominated television fiction in the 1950s, in part for reasons of convenience: the film western was mostly produced in the one-hour B-movie format, already calibrated for television programming, and the material infrastructures (ranches, trading posts, main streets, and saloons) were already in place and amortized. Furthermore, the production of "teleplays" was facilitated by the pillaging of a vast tradition of western novels and stories (Zane Grey, Max Brand). ${ }^{4}$

Ideologically, however, the simplified backdrop of the post-civil-war frontier town, its free citizens immune to problems of class or race, was the ideal setting for introducing action sequences into a moral theatre in which problems are posed by outside elements that disturb a generally harmonious micro-society (Rita Parks, 1982). ${ }^{5}$ At work here is a social vision that owes much to Puritan instincts about the world: the breeding ground of disorder lies in the inability of certain individuals to control themselves, rather than in real conflicts of interest, and the threat to the town is always first and foremost a threat to the recurring characters. A variation on this formula saw recurring characters visit a series of locations in turn, confronting and resolving local problems before they continued on their way (Wagon Train, Star Trek, The Fugitive, The Invaders, Time Tunnel). The moral universe of the television western, with its attention to personal excess, was mostly at odds with the culture of mass consumption. The exploitation of its generic popularity to sell advertising space intervened after the fact of production.

The 1960s saw a formal evolution in the classic series: the organization of an episode into modular segments, which preceded the emergence of writing teams. In its demonstration of modern consumer skills (wining, dining, seducing, being at ease in a cosmopolitan setting), the "pop series" broke markedly with the relentless moralizing of the western (Buxton, 1990). Characters in this type of series, like The Man from UNCLE and The Avengers, were closely related to the pop culture of the time, and were already optimally designed as ideological machines without psychological depth. This opened the way for the conquest of an emerging international market: the exploration of an individual's psychological makeup is always rooted in a national culture, and as such is more difficult to export. ${ }^{6}$ A memo for writers of the fourth and last season of The Man from UNCLE in 1967 expressed the need for humor, but stipulated that the protagonists should never joke when they are in danger (John Heitland, 1987). In other words, humor is reserved for sequences which are detachable from, and without influence on, the main storyline. The invention of modular segments allowed for a faster pace than the previous model based on theatrical drama, which was slowed down by the need to reveal and pass judgment on the moral value of each new character. Finally, this formal structure enables the rationalized distinction between a headquarter $\mathbf{r}_{2}$ where the recurring characters can establish themselves (through banter, running gags, etc.) in an ideologically controlled studio setting, and the outside world (themed studio settings, backlots for outdoor scenes), where they can apply their skills on a geopolitical stage. In consequence, this format requires that the recurring characters be the bearers of a positive (social) project, which legitimizes the use of violence or subterfuge in the accomplishment of their mission. ${ }^{7}$

\section{The "serialized" series}

Modular segments assumed a new role in the 1980s. Hill Street Blues (1981-7), followed by NYPD Blue (1993-2005) marked the emergence of the mixed series (or serialized series), a hybrid of the serial and the (classic) series which could also integrate elements of soap 
opera and situation comedy: each episode follows several plotlines, some resolve, some do not (Stéphane Benassi, 2000). After the introduction of more finely-tuned audience measurements by Nielsen in 1969 , advertisers were prepared to pay a premium for a "quality" (younger, more feminine, more urban) over a mass audience. This was a major step toward the real subsumption of the television series. ${ }^{8}$ After this, the series becomes decentered, either through a duo of dissimilar partners (Starsky and Hutch, Miami Vice) or, more radically, through a team consisting of diverse ethnic backgrounds (Hawaii 5-O). ${ }^{9}$ As it becomes incapable of a realist treatment of crime, which would involve a sociological explanation, and equally incapable of proposing a positive social project-not even the principled defense of the status quo-the police series takes refuge in interpersonal relations. Modular sequences reveal the personal problems of the recurring characters (alcoholism, sexual infidelity).

In its abandonment of the controlling male protagonist, the serialized series better "affords" (is less constrained in its material by) the absence of a positive project. In other words, it is the form best adapted to the ideological passivity of the series from the 1980s onward. In the episode "The Prodigal Son" (1986) of Miami Vice, a banker explains authoritatively that Wall Street is dependent on the capital flows of Colombian drug dealers. Drug consumption is shown to be widespread among ordinary citizens. The link between free enterprise and moral virtue, which provided an ideological bedrock for the classic series, falls apart here. So too does the pretension to realism, strained to the limit, which asks viewers to believe that regular narcs could operate as undercover dealers or hookers week after week, year after year, without being sniffed out. ${ }^{10}$ Powerless in the war on vice and decadence, the police agent could at least look at himself in the mirror and savor his personal victories. From this point on, the series form was condemned to find different strategies to confront what was, in effect, a structural passivity resulting from the dominance of finance over productive capital, and the consequent near impossibility of interventionist social policies.

In the 1990s, with The X-Files, the classic formula of stand-alone episodes was punctuated by occasional serial episodes, which revisited the overarching mythology of the series, namely the replacement of humans by a genetically mixed species, through the secret collaboration of aliens and the powers-that-be. The X-Files was one of the first series to experiment with the season-long narrative arc, in which plotlines left dangling are taken up over differing intervals. But it was in the emblematic 24 (2001-10) that the logic of serialization was taken to its extreme. In 24 , each season covered a single daylong intrigue sliced into 24 episodes of real time. The classic series was an ideal vehicle for the masculine hero who, alone or with partners, demonstrated his mastery of a given situation. The introduction of serialized elements juxtaposed private lives and discrete criminal cases, invariably exposing weaknesses, difficulties, and moments of doubt. Tara McPherson has described 24 as a "techno-soap" whose technological innovations (split screen, ticking clock) served to "remasculinize" the serial form, after its historical grounding in domestic drama associated with female audiences (McPherson, 2007). ${ }^{11}$

The mixed or serialized series now dominates the series form, but with internal variations, ranging from the serialized season (Dexter, Breaking Bad) to the predominantly classic form with serialized elements (CSI, in which forensic scientists, "behind the scenes," replace an ideologically spent police force). Narrative arcs can occur in every episode (24) or sparingly (Mentalist). The more a series contains serialized elements, the more it is prone to reboots and changes of direction. One new development is the thematic series in which character recurrence is limited to a single season (True Detective, Fargo).

The most important consequence of serialization is character inflation. No longer can problems be dealt with by a single white male (the 1950s TV western), or two partners (the 
1960s spy series). They now necessitate a strategically composed team of police officers (or lawyers, medical staff, etc.) in search of an elusive social equilibrium that might magically accommodate their various forms of diversity and personality traits: racial and ethnic categories, men and women, young and mature, gay and straight, liberal and conservative, and countless other possibilities. Hill Street Blues contained no fewer than 44 recurring characters (of which 20 were main characters). In general, some form of psychological development, synonymous with quality, required that these characters exist in and for themselves, their potential interactions harboring an exponential number of storylines. ${ }^{12}$

What then is the deeper meaning of the emergence and dominance of the decentered, serialized series? First, the recourse to multiple recurring characters, representing different approaches to the problems they confront, limits the damage of the structural passivity evoked earlier. Second, the very multiplicity of characters displaces the narrative center of gravity toward internal personal relations at the expense of sustained confrontation with social issues. Third, the serial form introduces elements of instability into a series, which was now forced to counter its own essentially entropic state through the creation of new characters and situations. The serialized series can only degrade, and thus corresponds to a society seen in this light.

In his discussion (1966) of Jules Verne's Mysterious Island, Pierre Macherey distinguishes between the representation of an ideological project (themes like scientific progress, the conquest of nature, etc.) and its figuration in concrete signs (characters, objects, habitats), which logically preexists any narrative movement. For Macherey, there is necessarily slippage, tension, and even contradiction between these two terms. ${ }^{13}$ This form of analysis is particularly adapted to the classic series, in which the figuration of an ideological project is congealed into an immanent framework, producing incremental value on a weekly basis (simple growth). If a project's figuration is too rigid, the margin for narrative variation is duly limited (for example, The Prisoner, 1967-8). Conversely, a figuration that is too vague and open-ended contributes little or nothing to a series' brand identity in the face of competition. The classic series was forced to negotiate a position between these two extremes. The multiplication of recurring characters and the integration of private lives made it more difficult for the classic series to return to its point of departure, opening up the contradiction between the representation and the figuration of its ideological project. Serialization in its various guises becomes the only solution to this formal problem.

Both the commodity status and the economic value of the television series have changed enormously since the 1950s. Until the 1990s, the series was an indirect commodity, a means of organizing regular audiences whose attention was sold in advance to advertisers. For a long time, the use value of being able to watch televised images free of charge in the comfort of the family living room preempted questions relating to their quality, but rising expectations led to the increase in the average cost of series in real terms (constant dollars) by a factor of over 3 between 1965 and 2015. ${ }^{14}$ The recent migration toward individual terminals and mobile devices, however, necessarily renews questions relating to form, commodity status, and the very future of televised fiction. The cost of early series was negligible, and most early television drama was seen as having no commercial value once broadcast. ${ }^{15}$ Incredibly, every episode of the first season of the classic British series The Avengers (1961) was erased so that the videotape could be reused; several years later, it was exported to 70 countries. Since the economic model was established in the 1960s, the value of a series is realized, if at all, a long way downstream in the syndication and international markets. Since the 1990s, the series has also been proposed as a direct commodity to the individual consumer, first in the form of videocassettes, and then as box set DVDs containing entire seasons. Another economic 
model is the branded package sold to cable subscribers, where it is the channel (HBO, etc.) that is the commodity (Szalay, 2014). While broadcast and programmed television viewing is on the decline, especially among younger viewers, the latest emerging market is online video on demand. The series is now a mixed commodity, both indirect and direct, whose future sources of revenue are correspondingly uncertain. Not the least of these uncertainties is the long-term economic viability of paid streaming sites.

The tendency away from indirect to direct commodity status, which also entails fewer episodes in a season, cannot but have an effect on the series form. With the gradual decline of broadcast television, it makes increasingly less sense to generate hundreds of episodes from the same fixed framework over a long period; in any case, the serial turn makes this more difficult to sustain. On services like Netflix, a whole season is available in advance, calling into question the historical notion of seriality. Pitched in the same manner as a feature film, the series tends toward a variant of the latter: a ten-hour renewable epic, whose viewing rhythm is discretionary.

\section{The real subsumption of the series form}

The argument for the real subsumption of the series form can now be made along several lines. First, the marketing department is now involved from the outset, before the production stage. As the sociologist John Caldwell has written,

any screenplay or project developed in primetime television or feature film today generates considerable attention and involvement at the earliest story sessions and producers' meetings by personnel from the firm's financing, marketing, coproduction, distribution, merchandizing and new media departments or divisions. [...] [A]t the pitch and script stages, story ideas will be developed as diversified entertainment properties....

(Caldwell, 2008)

In other words, the consumer is already conceptualized and targeted as an integral part of the production process.

In the case of Lost (2004-10), the producer, ABC, collaborated with amateur websites devoted to the series and participated in setting up a fan base to be mobilized as unofficial marketing auxiliaries. This has now become a common practice. At least one of the present functions of series is to help social media users "work" at constituting themselves as audience commodities, by providing cultural lubricant to define their profiles (for a discussion of the audience commodity debate, see Christian Fuchs, 2012). The series becomes a form of symbolic brand equity. Coming at this idea from another angle, Michael Szalay (2014) has suggestively argued, referring to several $\mathrm{HBO}$ series, that "dramas are futures markets [...] and should be understood as functionally equivalent to the class of financial instruments known as derivatives." Reproduction within and between seasons is conditioned by ongoing market research that determines the characters worth investing in, or liquidating. ${ }^{16}$

Second, real subsumption is also expressed in the way that the series form increasingly mirrors that of capitalist production itself. As a continual process of creating surplus value, capitalism depends on compound growth requiring exponential reinvestment, which exceeds the possibilities of productive capital (David Harvey, 2014). Marx calls this form of investment "fictitious capital" (credit, debt, speculation), whereby financial gain is dependent on the "fiction" that it will necessarily be convertible into productive capital (Marx, 1991). The inflation (accumulation) of characters in Game of Thrones, adapted from the books by George 
R. R. Martin, at once the most advanced formal expression of the serialized series and the most regressive in terms of social relations, embodies an economy of this type. By season 3, this series had exceptionally amassed 250 or so named characters (Wikipedia). Each new season, dozens of characters, and potential storylines are speculatively produced, only a few of which can be developed. ${ }^{17}$ Any purely psychological exploration is now contingent on budgetary considerations. ${ }^{18}$ The point here is that the forward movement of the serialized series is dependent on a form of inflation which, as in its stock exchange counterpart, must periodically undergo a cull before it collapses definitively (generally after six or seven seasons in the case of success). Unlike the guest characters in the classic series, those created in the serialized series never entirely disappear unless killed off.

Third, the serialized series tends to imitate finance capitalism in its internal structure. Potential plotlines are created continuously, from episode one, to maintain a relentless rhythm of accumulation. The concatenation of these formally resembles the circuits of capital discussed in volume two of Capital in which the movements of money capital (M-M'), commodity capital (C-C'), and productive capital are imbricated (Marx, 1992). Credit (or finance capital, or the ongoing willingness of an audience to invest in new plotlines) is essential to prevent paralyzing breakdowns or delays in the metamorphosis of one form of capital to another; similarly, the series needs a stock of virtual characters to fluidify its multiple developments.

In terms of Levine's "affordances," the genre that best corresponds to these formal demands is the saga, in which character inflation is structured around the links "afforded" by membership of families, clans, hordes, networks, and more recently criminal or antiterrorist organizations. Without these, a series like Game of Thrones would fall apart under its own weight, as did Lost, now seen in this respect as a counterexample. The dramatization of narrative links between "free" individuals cannot be satisfactorily contained within the form of the serialized series. Vampires, aliens, zombies, psychopaths, gangsters, survivors, sociopaths, and lawyers flourish however as so many expressions of a near "degree zero" of social relations reduced to naked self-interest and power games in which "no-one is innocent." logically passive ("winter is coming"), fatalistic, the serialized series is increasingly at pains to "afford" normalized, serial relations within the framework of a functioning capitalist society, still less one that is evolving to the tune of a progressive master narrative.

\section{Notes}

1 This difficulty could be circumvented in the case of the "classic" series of stand-alone episodes by treating a limited number of sample episodes as being representative of the whole. This option (used in Buxton, 1990) is no longer possible in the case of the "serialized" series, where one must wait until its termination before making definitive pronouncements, when a monographic treatment is less of a commercial proposition. A classroom exploitation of any one episode of, say, Game of Thrones, would be fairly meaningless.

2 One example will suffice: Earle Stanley Gardner wrote over 80 novels featuring the character Perry Mason between 1933 and 1973.

3 The passage to the fifty-two-minute format, generalized in the $1960 \mathrm{~s}$ for drama series, required at least one subplot and an in-house "treatment," and was therefore less conducive to professional writers of stories for the "pulp" magazines (Buxton, 2011). The turn to "serialized" series led to the generalization of specific writing teams of up to a dozen persons, headed by a showrunner.

4 It is important to emphasize the dependence during the early years of serialized television production on a preexisting tradition of genre literature (westerns, detective novels, fantasy, and romance). In the first season of Perry Mason (1957-8), 38 of the 39 episodes were adapted from the original novels by Earle Stanley Gardner, written over the period 1933-57; by the second season, adaptations had fallen to 11 out of 30 (Buxton, 2010). 
5 A memo for writers for Bonanza stipulated that "the townspeople must not turn against the Cartwrights... [who] are too intelligent in their behavior, too respected and too prominent to have such a thing happen" (Parks, 1982: 163).

6 The international market for series emerged rapidly at this time. Whereas The Lone Ranger was sold to 24 countries in 1961, The Man from UNCLE was broadcast in 60 countries several years later, followed by Mission: Impossible and Hawaii Five-O, which were exported to 87 and 80 countries (the socialist bloc being off limits). CSI was present in 150 countries in 2009 (Buxton, 2010).

7 In Mission: Impossible (1966-73), this involved a sexually and ethnically mixed, trans-class assemblage of actors, technicians, and managers (a "pop alliance") who clinically used their superior skills to intervene selectively against dictators and swindlers in foreign countries, always with a positive goal and outcome.

8 Since 2006, Nielsen IAG has measured, among other parameters, "viewer engagement" with series, an "active" mode of viewing expressed in the ability to remember minute narrative details. This explains why Lost, top ranked for viewer engagement in 2010, could charge significantly higher advertising rates than NCIS, despite the much larger audiences of the latter.

9 The choice of a disparate duo or socially diverse team of cops represents an ideological project in itself, an "upstream" resolution of social problems. For example, the pairing in Starsky and Hutch of the working-class (Jewish) Dave Starsky from New York and the college-educated Californian Ken Hutchinson in 1975 incarnates the "magical," national reconciliation of two social classes at odds over the Vietnam War. Add in a (grouchy) black boss and a (roguish) black informer for questions of race.

10 Even "quality" series like Breaking Bad and Dexter end up straining credibility to the limit for similar reasons.

11 Tellingly, one of the creators and leading writers on 24, Robert Cochran, began his career on the daytime serial Falcon Crest.

12 In the daytime serial, character inflation could be diluted and contained over many years.

13 In The Mysterious Island, the figuration (an uninhabited island, an (all male!) society in microcosm, and science incarnated by an engineer) of its ideological project contains no internal conflict that might propel the narrative. As the story advances, the protagonists are no longer the conquerors of nature, but the (passive) objects of an external force, the secret experiments of the misanthropic Captain Nemo. Similarly, in the classic series, the figuration of an ideological project is sometimes completely at odds with the constraint of renewable episodes, most clearly in the case of The Invaders (1967-8), where the project of a surreptitious alien invasion takes a back seat to weekly encounters with small-town, personal problems, far more important (Buxton, 1990: $14-15 ; 46-60)$.

14 Figure calculated from diverse sources relating to the cost of individual series in Buxton (2010). The weekly budget for decors and accessories for the daily sci-fi/western series Captain Video in 1953 was a mere $\$ 25$ (\$207 in 2015 dollars). An episode of the western series Cheyenne came to $\$ 75,000(\$ 470,000)$ in 1960 , and the spy series The Man from UNCLE, $\$ 155,000(\$ 906,000)$ in 1965. The average cost of an episode of a network or cable series in 2015 was between $\$ 3$ and $\$ 3.5$ million, and is typically "licenced" to channels at about $75 \%$ of its production cost. At the top end of the range, the average cost of an episode of the sixth season of Game of Thrones came to $\$ 6$ million, and in the seventh season between $\$ 10$ and $\$ 16$ million, comparable to a feature film outside Hollywood, but in a different league from the cinema blockbuster at \$150-200 million, plus marketing expenses.

15 As late as 1973, complete recordings of some 175 television series from the defunct network DuMont Television (1946-52) were unceremoniously dumped into New York harbor.

16 Sometimes in panic mode. Notoriously, 24 "misplaced" two presidents after assassination attempts, who disappeared from the series without further explanation. Initially, character inflation was seen as a form of insurance against excessive salary demands, each member of an expanded team being eminently replaceable.

17 For the two short final seasons, the producers made the conscious choice to close down the creation of new characters and plotlines, and instead to work on a projected derivative.

18 For example, during the first season of Game of Thrones, producer David Benioff spoke of writing supplementary, "intimate" exchanges between two actors, used to complete, at minimal cost, episodes whose allotted budget had run out (Cogman, 2012). 
19 In the words of an Islamic terrorist in 24 (4:09). It is in these terms that I express the insights into the journalist Brett Martin (2013) concerning the end of the (patriarchal) American Dream in a number of "quality" series from the decade 2000-10 (The Sopranos, Dexter, Mad Men, The Wire, Breaking Bad).

\section{References}

Adorno, T. (1954, ed. 1957). Television and the patterns of mass culture. In Rosenberg, B. and White, D. eds., Mass Culture. Glencoe, IL: Free Press.

Adorno, T., Adorno, G. and Tiedeman, R. (1997). Aesthetic Theory. New York: Athlone Press, p. 144.

Benassi, S. (2000). Séries et Feuilletons TV. Pour une typologie des fictions télévisuelles. Liège, Belgium: Editions du Céfal.

Buxton, D. (1990). From "The Avengers" to "Miami Vice". Form and ideology in the television series. Manchester, UK: Manchester University Press.

Buxton, D. (2010). Les Séries télévisées. Forme, idéologie et mode de production. Paris: L'Harmattan.

Buxton, D. (2011). Richard Matheson et The Twilight Zone: la terre étrangère interne. In Chenille, V., Dollé, M., and Mellier, D., eds., Richard Matheson. Il est une légende. Paris: Encrages Université, pp. 141-9.

Buxton, D. (2014). The end of capitalism, the end of the world. Out of focus, 5, http://v2.outoffocus. biz/david-buxton/.

Caldwell, J. (2008). Production Culture. Durham, NC: Duke University Press, pp. 232-3.

Cogman, B. (2012). Inside HBO's Game of Thrones. San Francisco, CA: Chronicle Books, p. 75.

Fuchs, C. (2012). Dallas Smythe Today - The Audience Commodity, the Digital Labour Debate, Marxist Political Economy and Critical Theory. Prolegomena to a Digital Labour Theory of Value. Triple C. Cognition, Communication, Cooperation, 10(2), pp. 692-740, http://www.triple-c.at.

Harvey, D. (2014). Seventeen Contradictions and the End of Capitalism. London: Profile Books, pp. 222-45. Heitland, J. (1987). The Man from UNCLE Book. New York: St Martin's Press, p. 188.

Jameson, F. (1990). Late Marxism. Adorno or the Persistence of the Dialectic. London: Verso, pp. 182-201.

Jameson, F. (1992). Signatures of the Visible. Abingdon, UK: Routledge, pp. 11-46.

Levine, C. (2015). Forms. Whole, Rhythm, Hierarchy, Network. Princeton, NJ: Princeton University Press, pp. 6-11.

Macherey, P. (2006). A Theory of Literary Production, 2nd ed. London: Routledge (original French edition, 1966).

Martin, B. (2013). Difficult Men. New York: Penguin Group.

Marx, K. (1992). Results of the immediate process of production. In Capital: Volume I. London: Penguin Books, pp. 1019-38. Ed. Ernest Mandel, trans. Ben Fowkes.

Marx, K. (1993. Capital: Volume II. London: Penguin Books, pp. 109-79.

Marx, K. (1993). Capital: Volume III. London: Penguin Books, pp. 525-42.

McPherson, T. (2007). Techno Soap. 24, Masculinity and Hybrid Form. In Peacock, S., ed., Reading 24. London: I. B. Tauris, p. 174.

Parks, R. (1982). The Western Hero in Film and Television. Ann Arbor: University of Michigan Research Press.

Porter, L. and Lavery, D. (2007). Unlocking the Meaning of Lost: An Unauthorized Guide. Naperville, IL: Sourcebooks.

Potte-Bonneville, M. (2015). Game of Thrones. Série noire. Paris: Les Prairies ordinaires.

Read, J. (2003). The Micro-Politics of Capital. Albany: State University of New York Press, pp. 103-51.

Szalay, M. (2014). HBO's Flexible Gold. Representations, 126(1), pp. 112-34. 